\title{
HVSR Analysis of Rockslide Seismic Signals to Assess the Subsoil Conditions and the Site Seismic Response
}

\author{
Alessia Lotti, ${ }^{1}$ Veronica Pazzi $\mathbb{D}^{1},{ }^{1}$ Gilberto Saccorotti, ${ }^{2}$ Andrea Fiaschi, ${ }^{3}$ \\ Luca Matassoni, ${ }^{3}$ and Giovanni Gigli ${ }^{1}$ \\ ${ }^{1}$ Department of Earth Sciences, University of Firenze, Via G. La Pira 4, 50121 Firenze, Italy \\ ${ }^{2}$ National Institute of Geophysics and Volcanology, Via della Faggiola 32, Pisa, Italy \\ ${ }^{3}$ Fondazione Parsec, Via di Galceti 74, Prato, Italy \\ Correspondence should be addressed to Veronica Pazzi; veronica.pazzi@unifi.it
}

Received 30 May 2018; Revised 14 September 2018; Accepted 1 October 2018; Published 1 November 2018

Academic Editor: Filippos Vallianatos

Copyright (C) 2018 Alessia Lotti et al. This is an open access article distributed under the Creative Commons Attribution License, which permits unrestricted use, distribution, and reproduction in any medium, provided the original work is properly cited.

\begin{abstract}
Many Italian rock slopes are characterized by unstable rock masses that cause constant rock falls and rockslides. To effectively mitigate their catastrophic consequence thorough studies are required. Four velocimeters have been placed in the Torgiovannetto quarry area for an extensive seismic noise investigation. The study area (with an approximate surface of $200 \times 100 \mathrm{~m}$ ) is located near the town of Assisi (Italy) and is threatened by a rockslide. In this work, we present the results of the preliminary horizontal to vertical spectral ratio analysis of the acquired passive seismic data aimed at understanding the pattern of the seismic noise variation in case of stress state and/or weathering conditions (fluid content and microfracturing). The Torgiovannetto unstable slope has been monitored since 2003 by Alta Scuola of Perugia and the Department of Earth Sciences of the University of Firenze, after the observation of a first movement by the State Forestry Corps. The available data allowed an extensive comparison between seismic signals, displacement, and meteorological information. The measured displacements are well correlated with the precipitation trend, but unfortunately no resemblance with the seismic data was observed. However, a significant correlation between temperature data and the horizontal to vertical spectral ratio trend of the seismic noise could be identified. This can be related to the indirect effect of temperature on rock mass conditions and further extensive studies (also in the time frequency domain) are required to better comprehend this dependency. Finally, the continuous on-line data reveal interesting applications to provide near-real time warning systems for emerging potentially disastrous rockslides.
\end{abstract}

\section{Introduction}

For many years, researchers have turned their attention to the massive problem of landslides in Italy. The topic is high on the agenda because roughly $70 \%$ of all the landslides in the European continent are concentrated in Italy [1]. As a consequence of steep slopes, high seismic activity, and soil and bedrock properties, many hillsides of the Italian valleys are characterized by unstable rock masses causing constant rock falls and rockslides of various sizes and types [2]. A thorough understanding of failure types, mechanisms, and possible causes of landslides is required to effectively mitigate their catastrophic consequences. Moreover, currently early warning systems (EWS) can be implemented in order to prevent loss of life and to reduce the economic and material impact of landslide events $[3,4]$. Nevertheless, frequently enough, it is not easy to find a technique able to provide an immediate alert [5]. Therefore, slope failure of rock masses represents an interesting case study for verifying the feasibility of using passive seismic monitoring in EWS. By means of the observation of the changes which occurred in the acquired signal, in fact, it could be possible to detect variations in the elastic parameters of the rock body related to changes in pore-fluid pressure, consolidation, and microfracturing that could forecast failure [6].

In the last years, besides the traditional geotechnical and structural monitoring (e.g., topographic total stations, extensometers, and inclinometers, [7]), new techniques have 
been used to characterize and monitor landslides: aerial photos and LiDAR $[8,9]$, GPS monitoring [10-12], InSAR and GB-InSAR technique [3, 13-15], laser scanner $[16,17]$, infrared thermography [18-20], and optic fiber strain sensors [21]. Shallow geophysical methods represent a valid complement to the aforementioned techniques [6, 22-27].

To verify the performance of a small-scale seismic network as part of an EWS, a pilot scale experiment was arranged to monitor an unstable rock mass. The test site is the Torgiovannetto quarry located in Umbria Region, one of the Italian Regions that is more prone to landslide. In general, quarries can be characterized as remarkably vulnerable areas, since their natural geomorphology is altered by excavating activities [28]. The data were collected during a 7-monthperiod monitoring. In this paper we present the results of the preliminary analysis carried out on the acquired data by means of the horizontal to vertical spectral ratio analysis (HVSR or H/V). These analyses were aimed at understanding the pattern of seismic noise variation in case of stress state and/or weathering conditions (fluid content and microfracturing) as the first step to set up a reliable EWS. The studied quarry rockslide was also extensively monitored since 2003 with traditional methods. Therefore, the multiparameter analysis was useful to understand the mechanisms that control the rockslide dynamics and to evaluate possible connection between rainfall/temperature/displacement and rockslide seismic activity. Thus, a comparison between the seismic data and both temperature and precipitation data is discussed, in order to highlight a correlation between them.

\section{The Study Area}

The Torgiovannetto test site is located in a micritic limestone former quarry (dismissed since the late '90s), $2 \mathrm{~km}$ NE from Assisi (Umbria Region in Central Italy) in the northward facing slope of Mount Subasio (red square in Figure 1). Landslides in Umbria occupy about $14 \%$ of the entire land cover $\left(8456 \mathrm{~km}^{2}\right)$ and affect many urban areas.

Mount Subasio (1109 $\mathrm{m}$ a.s.l.) is part of the UmbriaMarche Apennines, a complex fold and arcuate thrust belt that occupies the outer zones of the Northern Apennines of Italy. The belt developed during the Neogene as a result of the Ligurian Ocean closure, followed by the continental collision between the European Corsica-Sardinia Margin and the African Adria Promontory [29]. A northeast-directed compressional tectonic phase started during the middle Miocene and is still active near the Adriatic coast [30]. During the upper Pliocene an extensional phase started with a principal stress oriented about NE-SW that resulted in the dissection of the Umbria-Marche Apennines and the opening of a NWSE-trending set of continental basins. Mount Subasio area consists in a SSE-NNW trending anticline $[31,32]$ with layers dipping almost vertically in the NE side of the mountain with several NW-SE striking normal faults on the eastern and western flanks. The local geological formations, belonging to the Umbro-Marchigiana Sequence (from Calcare Massiccio to Marnoso Arenacea), represent the progressive sinking of a marine environment.
The study area consists mainly of micritic limestone belonging to the Maiolica Formation (Upper Jurassic-Lower Cretaceous) that widely outcrops in the area. The thickness of the Formation is about $100 \mathrm{~m}$ and is composed by white or light grey well-stratified micritic limestone layers, whose thickness ranges between $10 \mathrm{~cm}$ and $1 \mathrm{~m}$, and thin clay interlayers may sporadically occur. The site is also partially covered by very heterometric debris (from pebble- to cobblesized angular clasts, with scattered boulders, in a silty or coarse grained sandy matrix), some of which are of anthropogenic nature. The dip direction varies between $350^{\circ}$ and $5^{\circ}$, while the dip of layers from $25^{\circ}$ to $35^{\circ}$, which means that, in general, the layers' dip is in the same direction of the slope but with a gentler angle.

First deformations within the quarry site were observed in May 2003 by the State Forestry Corps, in the form of tension cracks in the vegetated area above and within the quarry front. From then, several monitoring campaigns were carried out by means of different techniques (topographic total station, inclinometers, extensometers, ground-based interferometric radar, laser scanner, and infrared thermal camera [7]). It is assured that the main predisposing factor of instability was the quarrying activity that heavily altered the original front. Actually the quarry is structured in four main terraces, that the dense vegetation prevents distinguish well them (refer to [4] for the quarry view from north to south), with an overall height of about $140 \mathrm{~m}$ (Figure 2). Nevertheless, earthquakes-induced landslides cannot be neglected among the instability factors. In fact, the link between earthquake and landslide is well documented in the literature, especially in the cases of high-magnitude seismic event [33-36]. For example, the seismic sequence that affected the area southeast of the quarry (Colfiorito basin) in the 1997-98 reached the Assisi area in a macroseismic intensity (MCS) Io $=8-9$ [37]. Therefore, the seismicity of the area surrounding the quarry is another important instability factor.

The main rockslide [38] in the Torgiovannetto quarry has a rough trapezoidal shape and covers about $200 \mathrm{~m} \mathrm{x} 100$ $\mathrm{m}$ in surface and $550 \mathrm{~m}$ a.s.l. and $680 \mathrm{~m}$ a.s.l. in altitude. The geometry and other soil parameters (such as densities and body wave velocities) are well known thanks to the geotechnical and geophysical investigations carried out on the site by Alta Scuola of Perugia and by the University of Firenze [4, 7]. Among these investigations, a passive seismic network in continuous recording was installed on this rockslide from December 2012 to July 2013. The "traditional" monitoring network was composed by 13 wire extensometers, 1 accelerometer, 1 meteorological station (composed of 1 thermometer and 1 rain gauge), and 3 inclinometers (Figure 2). The monitoring network, progressively enhanced and improved throughout the years, was completed with hydrological data [39], modelling computation analysis [7, 40], and the seismological stations. Nowadays, the active volume of Torgiovannetto rockslide is estimated to be about $182,000 \mathrm{~m}^{3}$. The upper boundary is defined by a big open subvertical fracture (Figure 2), a tension crack with an EW strike, which in some places displays a width up to $2 \mathrm{~m}$ and depth of about 20 meters [40]. 


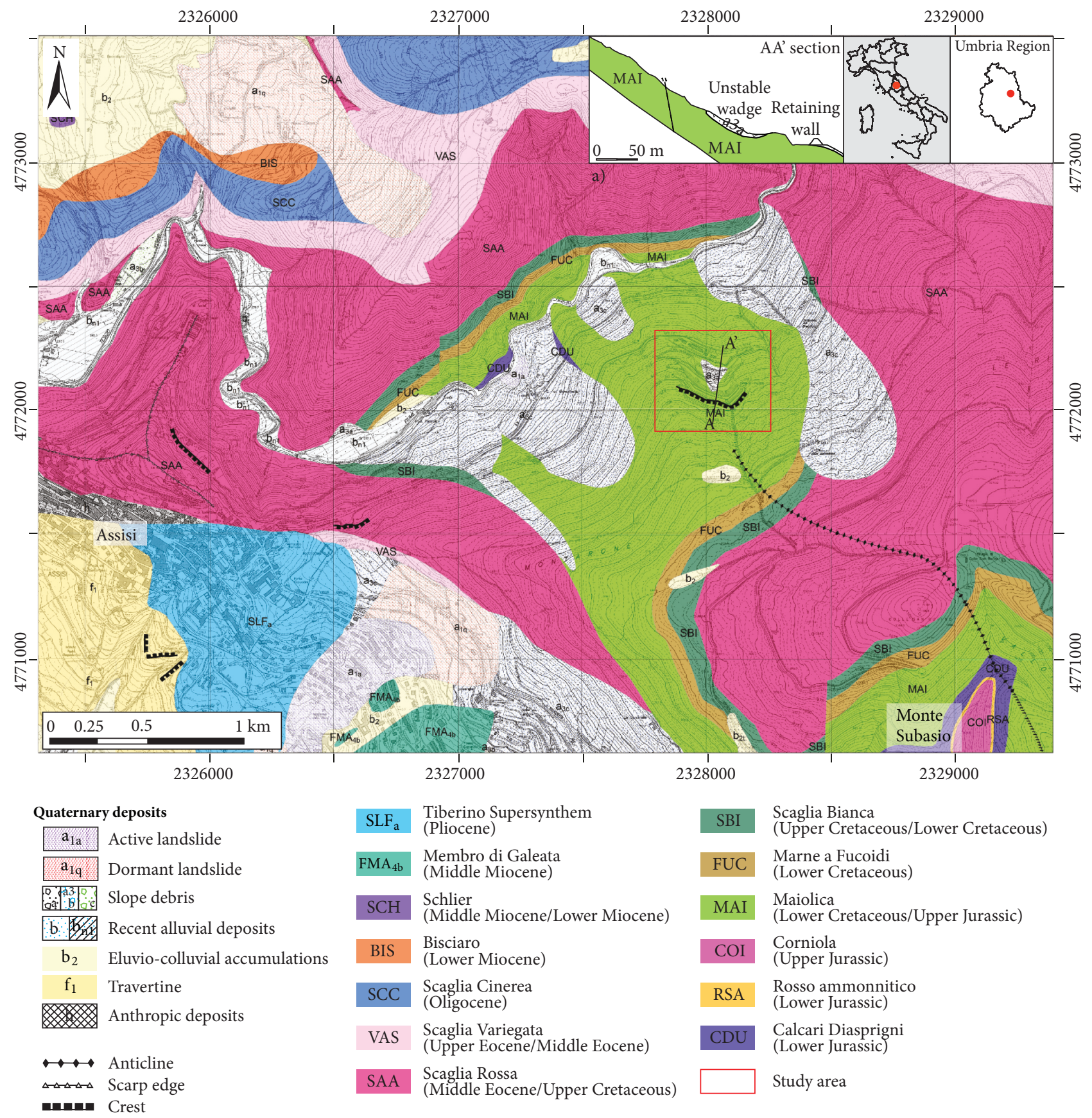

FIgURE 1: Geological map of the study area. (a) Geological cross-section of the investigated slope (modified from Balducci et al., 2011).

\section{Methods}

The HVSR technique was introduced for the first time by $[41,42]$. It is based on the ratio between the horizontal and vertical components of ground motion and it requires a 3-component sensor to acquire data. According to [43] microtremor energy consists mainly of $\mathrm{SH}$ waves, while, according to other authors, as discussed in [44], H/V peaks are related to Rayleigh waves. One of the striking features of the HVSR ratio is its stability in time, documented in many papers $[27,45,46]$. The HVSR curve allows gaining additional information about the underlying velocity profile at the site, especially when a strong different shear wave velocity exists between the shallow layer and the bedrock [47, 48]. The site effect amplification, in fact, could be caused by several geological conditions and one of them is the presence of a soft soil layer overlying a rigid half space. Nowadays, the HVSR is widely used both for environmental $[49,50]$ and for structural [51-53] problems. For a more detailed discussion about the seismic noise method please refer to the wide literature $[27,43,54-56]$. The main application of HVSR technique on landslide concerns the possibility to reconstruct 


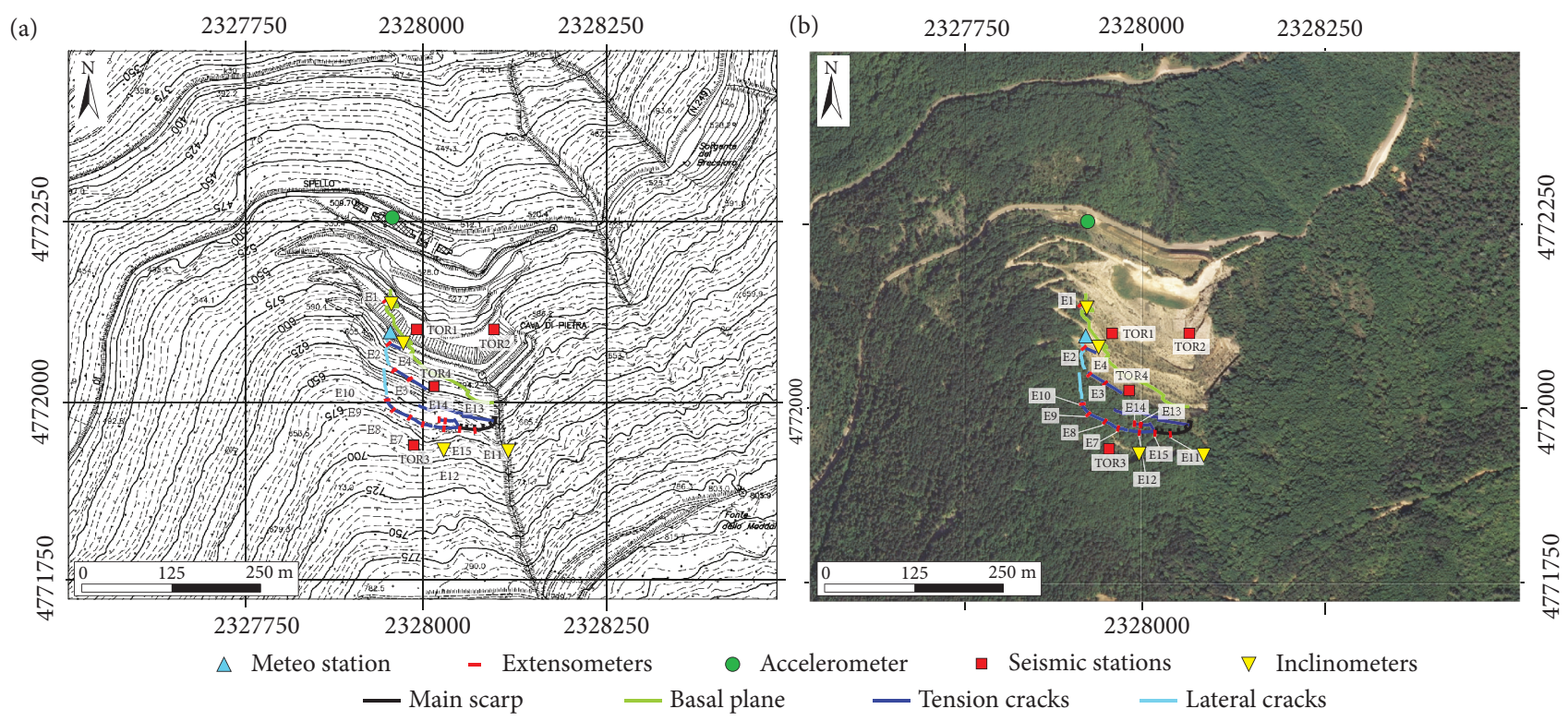

FIgURE 2: (a) Regional Topographic Map and (b) satellite view of the "traditional" monitoring network and the passive seismic array installed to monitor the Torgiovannetto quarry. Red squares represent the seismic stations, the light blue triangle represents the meteorological station, red lines represent the extensometers, and yellow triangles represent the inclinometers. The main scarp (black line), the basal plane (green line), and the tension and lateral cracks (dark blue and light blue, respectively) were detected by [4].

the geometry of the sliding mass and to detect the depth of the shear surface [27, 57-59] with a good approximation. This point is beyond the scope of this paper that, instead, aimed at the evaluation of the dynamic behaviour of the rock mass affected by the presence of fractures linked to the sliding wedge, searching for changes in its internal characteristics detectable by the HVSR shape $[6,23]$ that could be used in early-warning procedure.

At the Torgiovannetto quarry, seismic measurements were performed using a small-scale network composed by four seismic stations (TOR1, TOR2, TOR3, and TOR4; locations are shown in Figure 2). Due to the geomorphological characteristics of the site and the lack of access to the eastern part of the slope, the installation was really challenging. Station TOR4 was located on the sliding mass while the other three stations (TOR1, TOR2, and TOR3) were located at the edge of the quarry arranged in pairs with diametrically opposite position with respect to the centre of the landslide. This configuration (a reverse $\mathrm{Y}$ with respect to the sliding orientation) allowed us to retrieve punctual information both inside and outside the landslide. Each station with a SARA 24bit A/D converter (SL06) coupled with a SS45 tri-axial velocimeter sensor with a natural frequency of $4.5 \mathrm{~Hz}$ and transduction factor of $78 \mathrm{~V} / \mathrm{m} / \mathrm{s}$. Instruments response is flat down to $2 \mathrm{~Hz}$, with an upper-corner frequency of $100 \mathrm{~Hz}$. All of them were equipped with Global Positioning System (GPS) receivers for time synchronization. The sensors were placed on a concrete base with supporting plinth, isolated from the exterior in order to attain protection from severe weather conditions. Battery supply and digitizer, connected to the sensors through a connector cable, were housed in a separate case. Data were recorded in continuous mode at
$200 \mathrm{~Hz}$ sampling frequency, as the best compromise between signal resolution and data storage. Data acquisition was continuous for 210 days from December 7, 2012, to July 3, 2013 , except for some short intervals due to the batteries change. Data format of the seismic records retrieved from the converters SL06 is miniSEED ('Data-only' volume; http://ds.iris.edu/ds/nodes/dmc/data/formats/miniseed/).

Nevertheless, this format was mainly designed for the exchange of geophysical data and not for analysis. Therefore, first of all, recorded data were converted into a more suitable format for elaborations like SAC (Seismological Analysis Code; https://ds.iris.edu/files/sacmanual/manual/file_format.html). For each station, every 6 hours, three separate files were generated (Figure 3), which correspond to the east-west (SHE), north-south (SHN), and vertical or up-down (SHZ) components of ground velocity. The amplitude (y-axis) was expressed in counts, while the $\mathrm{x}$-axis in time (hours).

Data analysis was performed by means of Geopsy software (www.geopsy.org; cf. [53] as an example of application). For all the 3 components of ground motion the acquired data were detrended, mean-removed, and filtered. Then, each trace was divided into windows of $120 \mathrm{~s}$ length, and each window was tapered with a Tukey window and padded with zeros. The amplitude spectrum was evaluated via the Fast Fourier Transform (FFT); individual spectra were finally smoothed using a boxcar of $0.1 \mathrm{~Hz}$ width. The $\mathrm{H} / \mathrm{V}$ ratio was calculated for each window, and the final HVSR function was given by the average of the HVSRs over $6 \mathrm{~h}$ intervals. In this work the horizontal $(\mathrm{H})$ spectra have been computed by averaging E-W and N-S components using a quadratic mean, which shows a lower bias with respect to the simple arithmetic mean [52]. Finally, a special filtering process was 


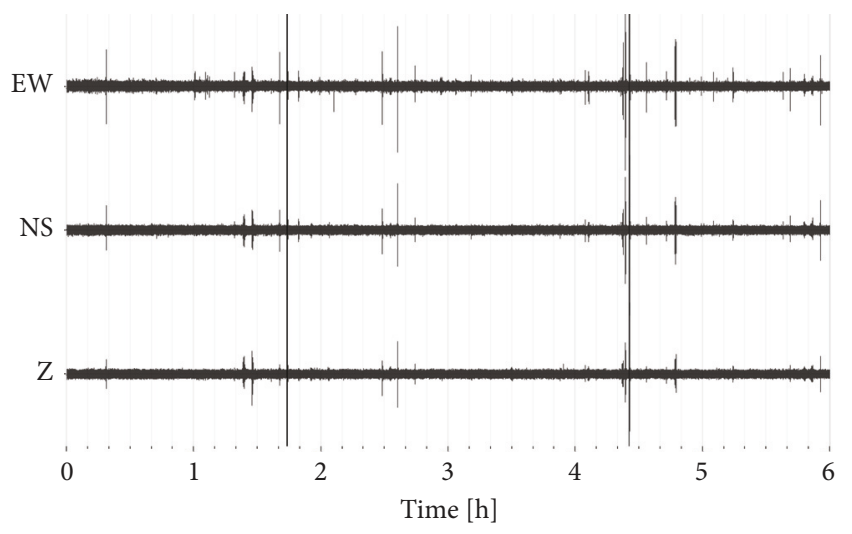

Figure 3: Example of a $6 \mathrm{~h}$ trace recorded during the monitoring period at TOR1 showing vibrations in three components (EW, NS, and vertical Z.)

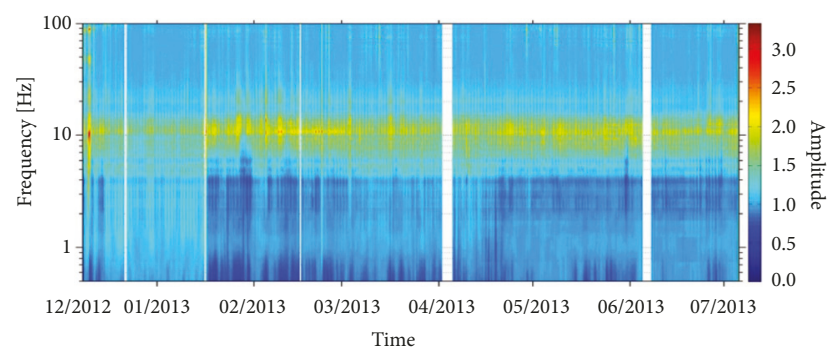

(a)

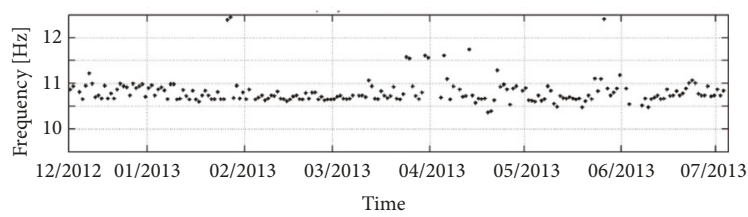

(b)

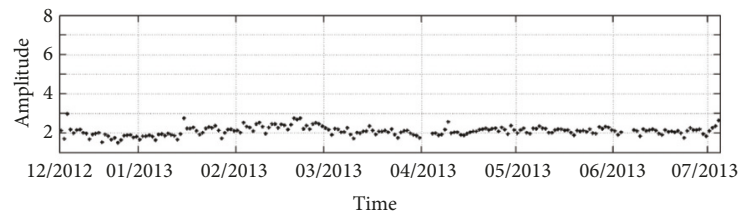

(c)

FIgURE 4: (a) The TOR1 HVSR amplitude, (b) the peak frequency distribution, and (c) the peak amplitude distribution over the whole monitoring period.

not applied since it did not significantly affect nonstationary noises as happened in other studies [60-62].

\section{Results}

The resonance frequency peaks, determined using the H/V method described above, were analysed for stations TOR1, TOR3, and TOR4 throughout the whole monitored period. The HVSR analysis of station TOR2 is not presented here because of the typical flat shape of the outcropping seismic bedrock [55]. The TOR1 HVSR (Figure 4) exhibits the highest

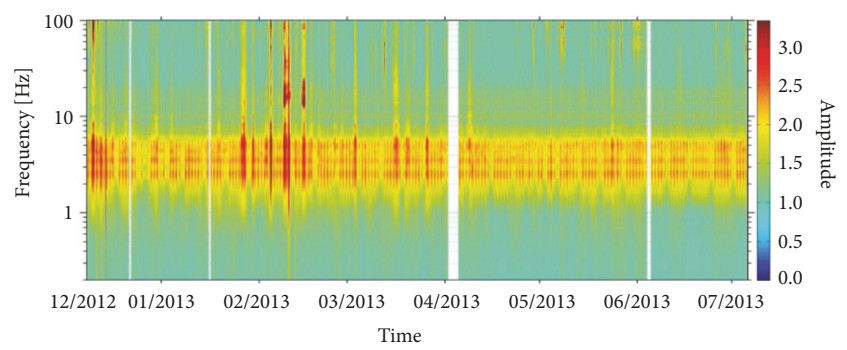

(a)

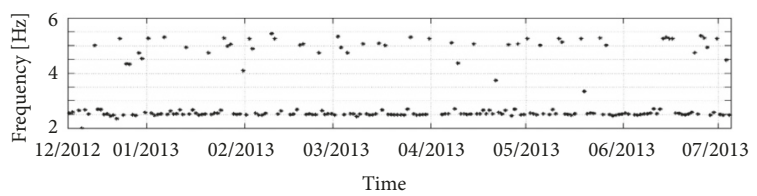

(b)

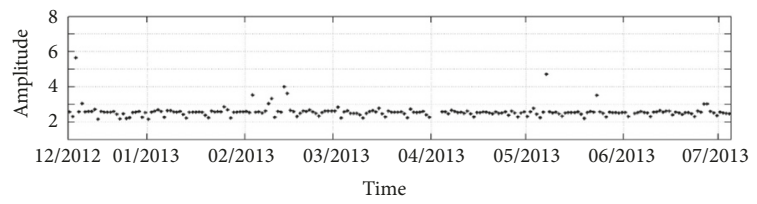

(c)

FIGURE 5: (a) The TOR3 HVSR amplitude, (b) the peak frequency distribution, and (c) the peak amplitude distribution over the whole monitoring period.

amplitudes over the frequency band of $4.5 \mathrm{~Hz}$ to $13 \mathrm{~Hz}$ with a stable peak around $10.5 \mathrm{~Hz}$ whose amplitude is generally slightly above 2 . Throughout the observation period, both, peak amplitude and frequency, did not exhibit any particular trend, with the exception of a slight increase in amplitude within the period of January to mid-March, 2013. The TOR3 HVSR (Figure 5) is characterized by more closely spaced peaks of amplitude higher than 2, coalescent in the spectral band spanning from 2.5 to $6 \mathrm{~Hz}$. Two main peaks are present: one, more frequent at $2.5 \mathrm{~Hz}$ and the other at $5 \mathrm{~Hz}$. This behaviour suggesting that the medium properties are likely subjected to slight, periodic variations potentially related to temporary fluctuation in water content that influences the propagation velocity.

At TOR4 (Figure 6) the HVSR exhibits two main peaks at frequencies of roughly $2.7 \mathrm{~Hz}$ and $5.5 \mathrm{~Hz}$. The amplitude of these peaks varies according to a characteristic and systematic daily, and therefore weekly, behaviour, in which the largest amplitudes of noise are higher. This could be associated with (a) an artefact related to the internal electronic noise of the instrument, whose effects become relevant when the ground vibrations have very low amplitude, such as night time or during the weekend, or (b) the variations of the noise wavefield, as a consequence of the activation of different sources related to anthropogenic activities. Beginning in April, 2013, the amplitudes of these peaks start increasing from the values of 3 , and by the end of the monitoring period they attain values around 5, that is, about $65 \%$ greater than those observed during the early phases of the experiment. Such amplitude increase is likely to reflect a corresponding 


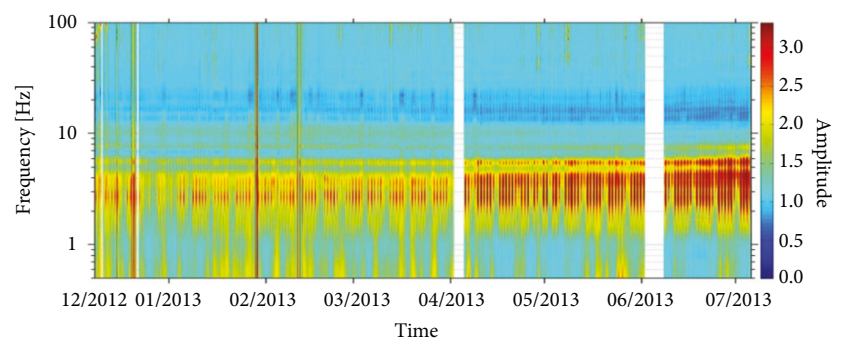

(a)

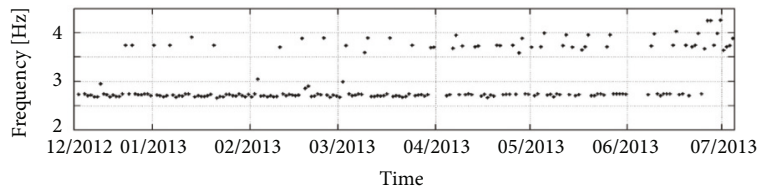

(b)

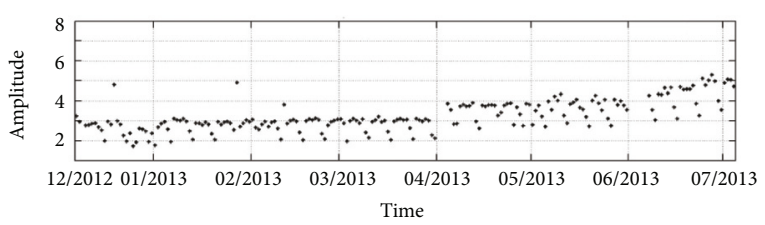

(c)

FIgURE 6: Near here: (a) The TOR4 HVSR amplitude, (b) the peak frequency distribution, and (c) the peak amplitude distribution over the whole monitoring period.

increase of the impedance contrast between the unstable mass and the underlying solid bedrock. However, the peak frequency remains stable in time, indicating that both thickness and velocity of the shallowest layer remain substantially unchanged. Thus, an increment in the velocity and/or density of the underlying layer must be invoked in order to explain the inferred impedance variations. Potential phenomena provoking this possible velocity increase will be discussed in the following.

Also, the HVSR directivity throughout the 7 months of recording was analysed. As an example, contour maps in Figures 7(a) and 7(b) compare the medium directionality of data acquired in December 2012 and July 2013, respectively. For the two different intervals, the directivity at stations TOR1, TOR2, and TOR3 stayed substantially unchanged. On the other hand, the TOR4 polarization direction between the two periods change slightly (Figure 8), even though for the later interval directivity is clearer as a consequence of the amplitude increase of the horizontal components, as also manifested by the growing number of the HVSR peaks (Figure 6). This suggests that the observed temporal variations in the HVSR plots are not due to changes in the distribution of active sources; if this would be the case, consequently the polarization direction should most likely have changed.

\section{Discussion}

Assuming that the HVSR is strictly related to the dynamic properties of the medium and that it is supposed to be stable if no change occurred in the velocity and/or density of the ground [63], results from HVSR analyses can be summarized as follows: (i) there are clear configurations of quasiconstant or slowly varying contiguous frequencies whose $\mathrm{H} / \mathrm{V}$ peak values depend on the considered station; (ii) the stations located on the sliding mass (TOR4) and at its head (TOR3), on potentially loose section, show an amplitude peak which is sharper and larger than those observed at the stations settled downstream. At TOR4, the amplitude variations of the HVSR cannot be unequivocally interpreted. However, the overall stationarity of the polarization properties suggests that those changes most likely reflect a variation in the acoustic properties of the medium rather than a change in the distribution of noise sources.

As mentioned in the Introduction section the quarry rockslide was extensively monitored since 2003 with traditional methods. Among these, as shown in Figure 2, there were 13 extensometers. All the extensometer data (E1-E15 in Figure 2) were individually normalized and compared with the measured cumulative rainfall in order to highlight a possible linear correlation between two different time series. The corr function in MATLAB was employed to both evaluate the linear (or rank) correlation (Rho) and perform a hypothesis test. The hypothesis was of no correlation against the alternative that there is a nonzero correlation (Pval) assuming by the authors that the correlation between two data is significant if Pval is sufficiently small $(<0.05)$. Table 1 shows the values obtained for each comparison.

The results of the correlation analysis clearly show that the deformational fields in the upper section of the quarry (E7, E8, E9, E10, E13, E14, located on the main cracks whose widths enlarge up to $2 \mathrm{~m}$ from East to West) and in the western part of the quarry (E2, located on the lateral crack) are strictly related to the seasonal rainfall, since the Pval values are very small (exponent lower than -100). This behaviour could be explained taking into account that, at sites where opening of the fractures is significant, pore water pressures in the fractures/cracks can critically influence the stability of rock. Unfortunately, because of a problem in the instrumentation, no data are available on the water level in the cracks. Moreover, from a qualitatively point of view, looking at Figure 9, it is possible to assess that periods characterized by the main soil movements (highlighted by the vertical sections of the extensometer curves) follow periods with higher rainfall (highlighted by the vertical sections of the cumulated rain curve). In particular, this behaviour is clear at the half of January, and at the end of February and May. The rainfall also seems to have a weaker but still significant influence on the deformations measured by E11, E3, E4, and E15 (Figure 9) while an inverse correlation exists with the data recorded by E1 (located in correspondence of the basal plane). Finally, there is no evidence of correlation for E12 data neither with the rain trend nor with the temperature variation. Unfortunately, there are no superficial evidences that could justify this behaviour, apart from the fact that E12 is located in correspondence of a junction between two main fractures (Figure 2). Perhaps its behaviour is caused by this junction (i.e., the highest movements are recorded by the 

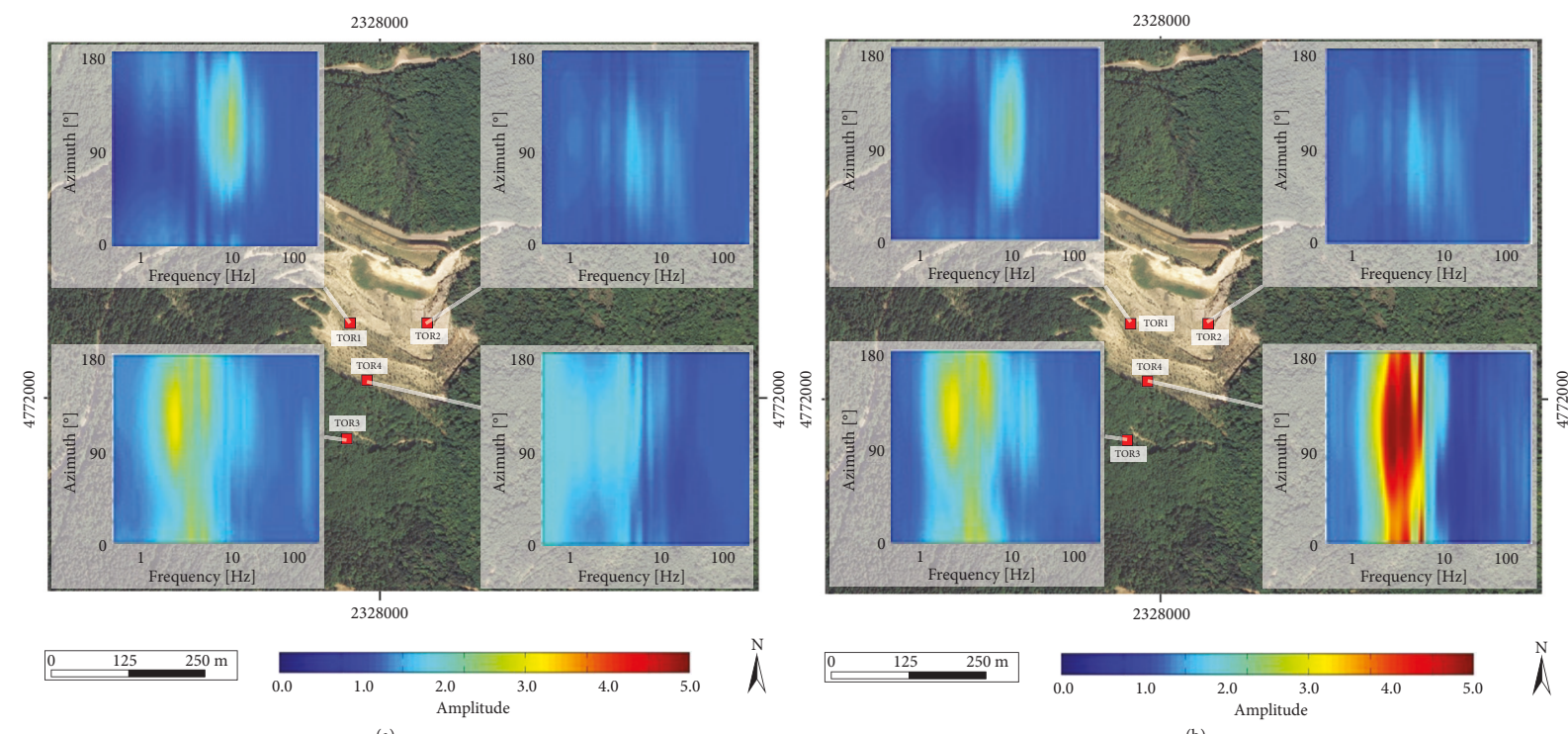

(b)

FIgURE 7: The HVSR directivity in (a) December 2012 and (b) July 2013.

TABLE 1: Correlation test between cumulative rainfall and extensometer data (Cum_RAIN - Ei, where i=1, 2. . 15), and temperature and E12 extensometer data (Temp - E12).

\begin{tabular}{lccccc}
\hline Correlation test & Rho & Pval & Correlation test & Rho & Pval \\
\hline Cum_RAIN - E1 & -0.8674 & $9.1381 \mathrm{e}^{-64}$ & Cum_RAIN - E10 & 0.9724 & $5.5739 \mathrm{e}^{-131}$ \\
Cum_RAIN - E2 & 0.9822 & $4.0970 \mathrm{e}^{-150}$ & Cum_RAIN - E11 & 0.8782 & $2.9209 \mathrm{e}^{-67}$ \\
Cum_RAIN - E3 & 0.8326 & $6.7328 \mathrm{e}^{-51}$ & Cum_RAIN - E12 & 0.1336 & $5.5500 \mathrm{e}^{-2}$ \\
Cum_RAIN - E4 & 0.8296 & $1.6040 \mathrm{e}^{-53}$ & Cum_RAIN - E13 & 0.9860 & $1.1666 \mathrm{e}^{-67}$ \\
Cum_RAIN - E7 & 0.9746 & $1.7970 \mathrm{e}^{-134}$ & Cum_RAIN - E14 & 0.9845 & $2.7311 \mathrm{e}^{-156}$ \\
Cum_RAIN - E8 & 0.9826 & $3.7711 \mathrm{e}^{-151}$ & Cum_RAIN - E15 & 0.9633 \\
Cum_RAIN - E9 & 0.9833 & $7.4087 \mathrm{e}^{-153}$ & Temp - E12 & 0.1564 & $1.5301 \mathrm{e}^{-118}$ \\
\hline
\end{tabular}
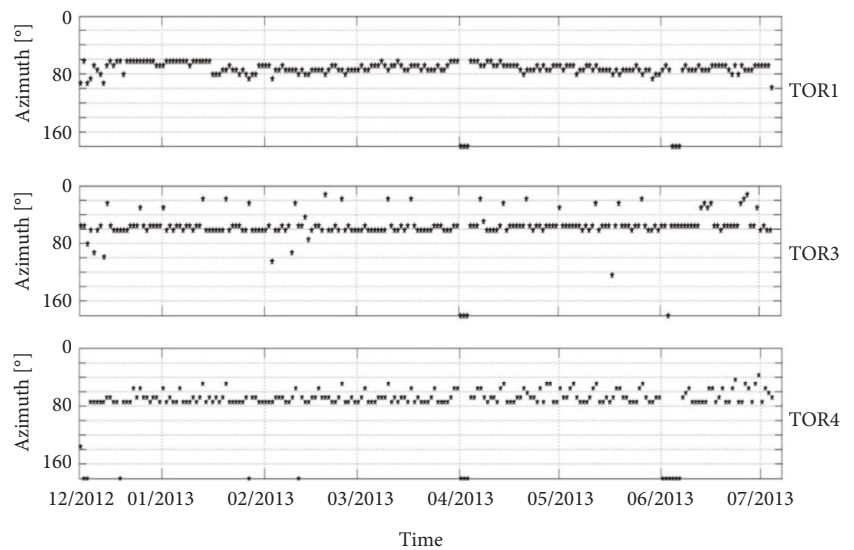

FIgURE 8: The peak azimuth distribution at TOR1, TOR3, and TOR4 over the whole monitoring period.

extensometer around), or otherwise it could be possible that some errors in the data registration occurred.

A good match (Rho: 0.7147; Pval 9.3923 $\mathrm{e}^{-30}$ ) is obtained by comparing the TOR4 HVSR amplification value and temperature variation (Figure 10). This could be caused by the water content variation in the medium (water content alternatively empties and fills the rock pores) and consequently the relative $V_{R}$ variation, related to changes in the HVSR amplification value. The saturation of pores with water, in fact, tends to increase the velocity of P-waves (which propagate more efficiently through water than air), also increasing the Poisson ratio. This has a strong influence on the Rayleigh waves and, in particular, on the ellipticity of the particle motion with a consequent increase of the ratio between the horizontal component $\mathrm{H}$ and the vertical one $\mathrm{V}$ of ground motion [64-66].

To justify the strong resemblance that emerges by comparing the temperature trend and that of the $\mathrm{H} / \mathrm{V}$ recorded at TOR4, a direct dependency of this latter parameter on the meteorological conditions could be supposed. This behaviour is suggested in [67] that ascribes a fundamental role to barometric conditions variation concerning the composition of the noise wavefield. In [68] this behaviour is related to microseismic frequencies (lower than $1 \mathrm{~Hz}$ ) and is related to oceanic storm waves. Reference [69] observes similar phenomena at very high latitudes: in that case the variations could be explained by cycles of freezing and thawing 


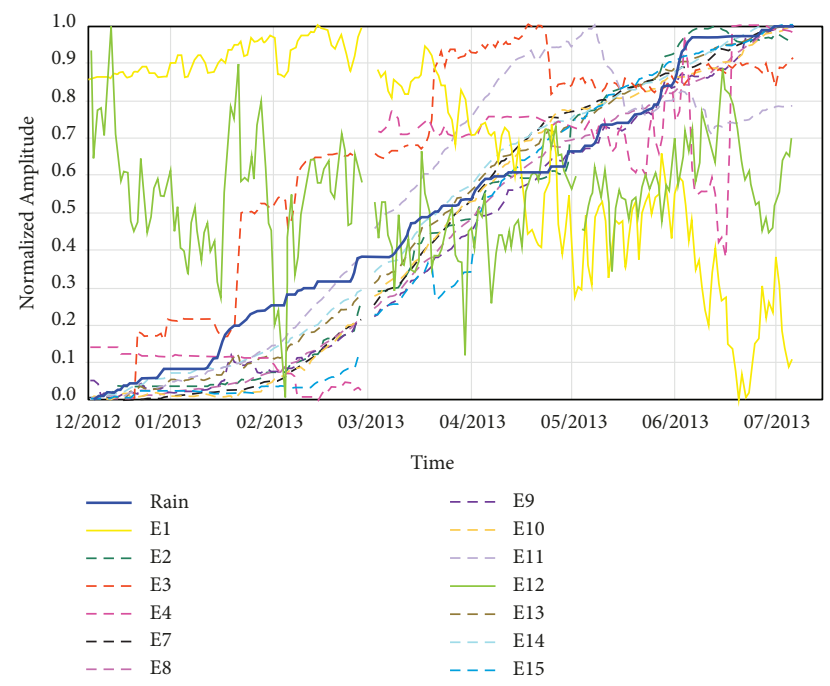

(a)

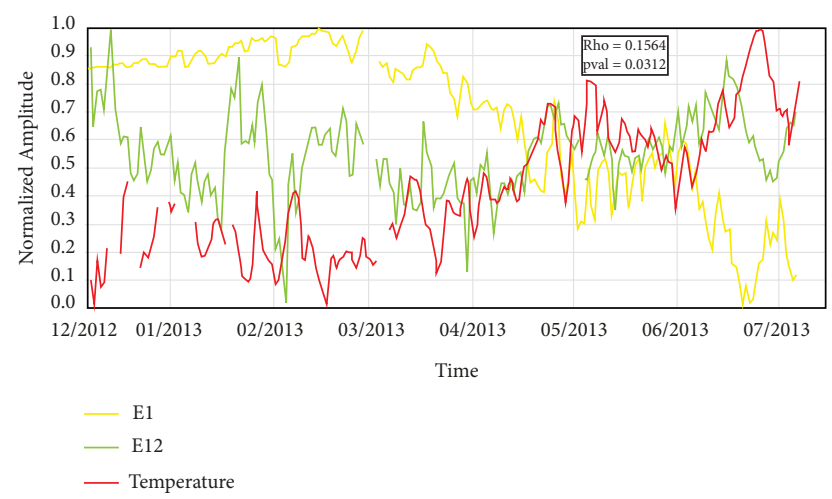

(b)

FIGURE 9: (a) The extensometer and rain trends and (b) two selected extensometer and temperature trends. The E2, E7, E8, E9, E10, E13, E14 trends show a clear correlation with the precipitation; the E3, E4, E11, E15 trends show a weaker correlation with the rain; the E1 trend shows an inverse correlation with the rain; the E12 trend does not show correlation either with rain or with temperature.

that crumble the rock surface and change their acoustic properties. Moreover, [70] points out how the HVSR amplitude could be affected by the local meteorological conditions (e.g., the wind). If this would be the case, an extended dataset $(>1 \mathrm{yr}$ ) would be necessary in order to clarify whether the observed variations at TOR 4 are part of cyclical phenomenon occurring over longer periods as a consequence of seasonal changes. Unfortunately, at the Torgiovannetto quarry it was not possible to extend the experiment over longer time intervals because of the hard acquisition conditions. Nevertheless, the hypothesis that the HVSR amplitude value is directly related to meteorological factors can be excluded in Torgiovannetto area. All the stations, in fact, given their small spacing, should have shown the same amplitude increase. At the contrary, TOR1 shows a minimum in January 2013 and relatively constant values in the other months; TOR3 shows pronounced maxima on December 2012 and February 2013; TOR4 shows an increasing trend from January to July 2013.

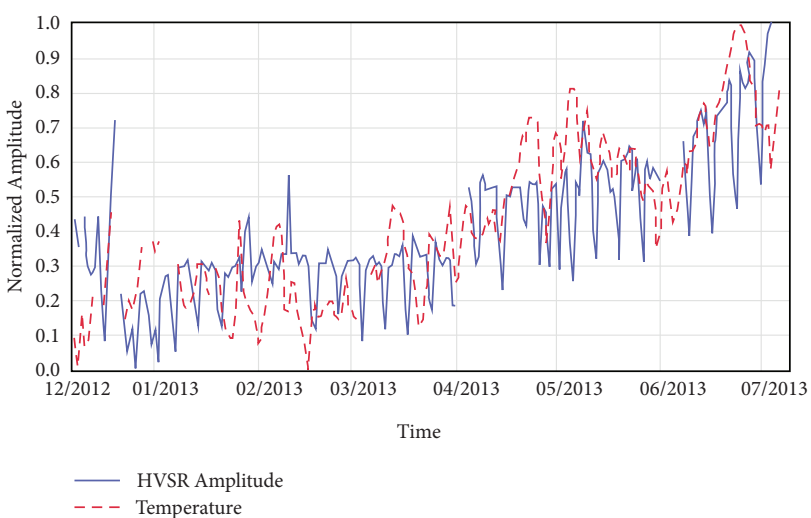

(a)

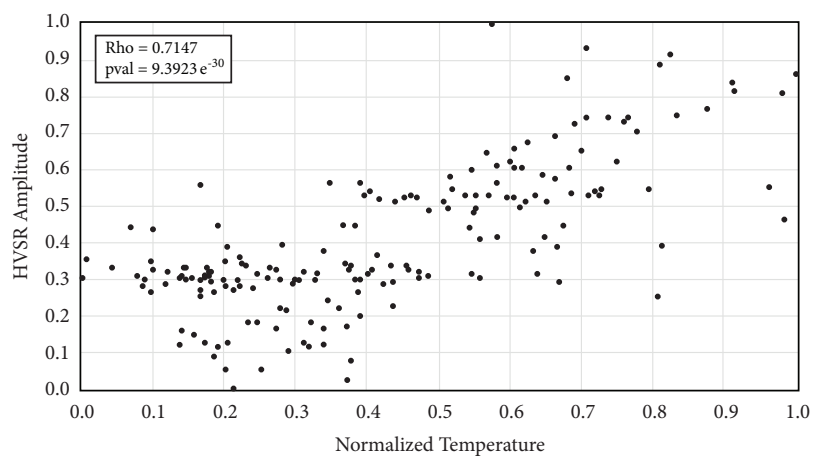

(b)

FIGURE 10: (a) HVSR peak amplitude at TOR4 and temperature. (b) Correlation between the HVSR TOR4 peak amplitude and the normalized temperature.

These H/V frequency variations could be associated with a different depth of fracturing (i.e., at site TOR1 fractures are shallower/near to the surface while at sites TOR3 and TOR4 they could be observed at depth) since the penetration of the surface waves is related to the frequency, but there are no experimental data on the depth of the fractures. Moreover, the surface geology at site TOR1 is characterized by stiffer or thicker geological unit, as indicated by the H/V frequency at $4.5 \mathrm{~Hz}$. The surface geology at site TOR3 is characterized by softer/or thinner geological unit, as indicated by the H/V frequency at $2.5 \mathrm{~Hz}$.

Probably the temperature variation does not directly affect the H/V amplitude but is responsible of other mechanisms like: (i) increasing of the fracturing degree of the medium acting directly on the dilatancy of the rocks (an increase in the medium fracturing may result, directly or, more often, indirectly, in density or velocity of propagation variations); (ii) influencing the water content of the superficial layer leading to an increase of the wave velocity of this portion of the slope. This hypothesis is supported by the variation in the impedance contrast which occurred with the approach of the hot season (early April, 2013) and therefore higher temperature (i.e., the water in the superficial layers is more prone to evaporate with the higher temperature). 
Unfortunately, at the present state the lack of evidence of surface displacements corresponding to the observed variations in the HVSR amplitude trend foreclosed any possibility of threshold identification that could be used as an EWS. It could be interesting to evaluate this technique as a surveillance method when it can be calibrated on monitoring intervals characterized by a high rate of surface activity or over longer period in order to explain the cyclical variation of that parameter.

\section{Conclusion}

Implementing an EWS is a challenging issue in landslide monitoring. To verify the usefulness of seismic noise analysis as part of an EWS, a pilot scale experiment was arranged to monitor an unstable rock mass. A 7-month period of passive seismic data was analysed by means of the H/V method. Possible connection between rainfall/temperature/displacement and rockslide seismic activity was evaluated, and the hypothesis that the HV amplitude value is directly related to meteorological factors can be excluded. On the contrary, the $\mathrm{H} / \mathrm{V}$ observed variations with time are interesting, in that they potentially reveal changes of subsoil site conditions and have also implications for the assessment of site response to seismic shaking. The presented analysis was just the first step to employ $\mathrm{H} / \mathrm{V}$ variations in an EWS. Many efforts, in fact, have to be employed both to understand how the observed variations are correlated with slope stability conditions and to set up a reliable EWS. For the first point (a) a longer time acquisition period and (b) a comparison with many other parameters to model and interpret in a quantitative way are needed. There are many factors (like cracks, joints, rock diagenesis, and saturation), in fact, that could cause velocity or density variations and therefore influence the ellipticity and/or polarization of the surface waves. For the second point, there are some open questions like, (a) what is the main information that the EWS will receive, (b) how this information will be processed, (c) what are the preferred time responses, and (d) how the potential variations and/or errors from (a) and (b) will affect the false alarm/no alarm ratios of the EWS. Nonetheless, the rapid technological advances increasing the speed in acquisition, transmission, and processing of data suggest that it is clearly worthy to proceed in the field of seismic monitoring of unstable slopes.

\section{Data Availability}

The data used to support the findings of this study are available from the corresponding author upon request.

\section{Conflicts of Interest}

The authors declare that they have no conflicts of interest.

\section{Acknowledgments}

The Department of Earth Sciences (Unifi-DST) supported this research as part of its program to improve rockslide early warning system (PRIN 2009 - Advanced monitoring techniques for the development of early warning procedures on large rockslides - prot. 20084FAHR7_001). We gratefully acknowledge Sara Electronic Instrument for providing the devices installed at the four seismic stations. We thank Massimiliano Nocentini and Luca Lombardi (Unifi-DST) for the huge efforts deployed to install, maintain, and make available the microseismic data and Francesco Ponziani (Centro Funzionale Regione Umbria) for providing meteorological data and very helpful comments and suggestions for the manuscript. Thanks are also due to Prof. Nicola Casagli (Unifi-DST) whose initial review was very helpful. The authors are also grateful to the anonymous reviewers for providing very helpful comments to improve the manuscript.

\section{References}

[1] M. Van Den Eeckhaut and J. Hervás, "State of the art of national landslide databases in Europe and their potential for assessing landslide susceptibility, hazard and risk," Geomorphology, vol. 139-140, pp. 545-558, 2012.

[2] P. M. Atkinson and R. Massari, "Generalised linear modelling of susceptibility to landsliding in the Central Apennines, Italy," Computers \& Geosciences, vol. 24, pp. 373-385, 1998.

[3] W. Frodella, T. Salvatici, V. Pazzi, S. Morelli, and R. Fanti, "GbInSAR monitoring of slope deformations in a mountainous area affected by debris flow events," Natural Hazards and Earth System Sciences, vol. 17, no. 10, pp. 1779-1793, 2017.

[4] E. Intrieri, G. Gigli, F. Mugnai, R. Fanti, and N. Casagli, "Design and implementation of a landslide early warning system," Engineering Geology, vol. 147-148, pp. 124-136, 2012.

[5] L. Zan, G. Latini, E. Piscina, G. Polloni, and P. Baldelli, "Landslides early warning monitoring system," in Proceedings of the 2002 IEEE International Geoscience and Remote Sensing Symposium (IGARSS 2002), pp. 188-190, Canada, June 2002.

[6] D. Arosio, L. Longoni, M. Papini, M. Boccolari, and L. Zanzi, "Analysis of microseismic signals collected on an unstable rock face in the Italian Prealps," Geophysical Journal International, vol. 213, no. 1, pp. 475-488, 2018.

[7] G. Gigli, E. Intrieri, L. Lombardi et al., "Event scenario analysis for the design of rockslide countermeasures," Journal of Mountain Science, vol. 11, no. 6, pp. 1521-1530, 2014.

[8] J. McKean, E. Bird, J. Pettinga, J. Campbell, and J. Roering, "Using LiDAR to objectively map bedrock landslides and infer their mechanics and material properties," in Proceedings of the Denver Annual Meeting, vol. 36, p. 332, Geological Society of America Abstract with Programs.

[9] J. McKean and J. Roering, "Objective landslide detection and surface morphology mapping using high-resolution airborne laser altimetry," Geomorphology, vol. 57, no. 3-4, pp. 331-351, 2004.

[10] J. A. Gili, J. Corominas, and J. Rius, "Using Global Positioning System techniques in landslide monitoring," Engineering Geology, vol. 55, no. 3, pp. 167-192, 2000.

[11] J.-P. Malet, O. Maquaire, and E. Calais, "The use of global positioning system techniques for the continuous monitoring of landslides: Application to the Super-Sauze earthflow (Alpesde-Haute-Provence, France)," Geomorphology, vol. 43, no. 1-2, pp. 33-54, 2002.

[12] C. Squarzoni, C. Delacourt, and P. Allemand, "Differential single-frequency GPS monitoring of the La Valette landslide 
(French Alps)," Engineering Geology, vol. 79, no. 3-4, pp. 215229, 2005.

[13] G. Antonello, N. Casagli, P. Farina et al., "Ground-based SAR interferometry for monitoring mass movements," Landslides, vol. 1, no. 1, pp. 21-28, 2004.

[14] N. Casagli, F. Catani, C. Del Ventisette, and G. Luzi, "Monitoring, prediction, and early warning using ground-based radar interferometry," Landslides, vol. 7, no. 3, pp. 291-301, 2010.

[15] F. Fidolini, V. Pazzi, W. Frodella, S. Morelli, and R. Fanti, "Geomorphological characterization, monitoring and modeling of the Monte Rotolon complex landslide (Recoaro Terme, Italy)," Engineering Geology for Society and Territory - Volume 2: Landslide Processes, pp. 1311-1315, 2015.

[16] N. Casagli, G. Gigli, E. Intrieri, L. Lombardi, M. Nocentini, and W. Frodella, "Applicazione di nuove tecnologie di indagine e monitoraggio per fenomeni di instabilità in ammassi rocciosi," in Nuovi Metodi di Indagine, Monitoraggio e Modellazione degli Ammassi Rocciosi, G. Barla, M. Barla, A. M. Ferrero, and T. Rotonda, Eds., pp. 137-158, Celid, Torino, 2012.

[17] G. Gigli and N. Casagli, "Extraction of rock mass structural data from high resolution laser scanning products," in Landslide Science and Practice - Volume 3: Spatial Analysis and Modelling, C. Margottini, P. Canuti, and K. Sassa, Eds., pp. 89-94, Springer, Berlin Heidelberg, 2013.

[18] I. Baron, D. Beckovsky, and M. Lumir, "Infrared thermography sensing for mapping open fractures in deep-seated rockslides and unstable cliffs," in EGU General Assembly, pp. 7-12, Vienna, Austria, 2013.

[19] W. Frodella, S. Morelli, and V. Pazzi, "Infrared thermographic surveys for landslide mapping and characterization: The Rotolon Dsgsd (Northern Italy) case study," Italian Journal of Engineering Geology and Environment, vol. 2017, no. 1, pp. 7784, 2017.

[20] W. Frodella, F. Fidolini, S. Morelli, and V. Pazzi, "Application of infrared thermography for landslide mapping: The rotolon DSGDS case study," Rendiconti Online Societa Geologica Italiana, vol. 35, pp. 144-147, 2015.

[21] J. R. Moore, V. Gischig, E. Button, and S. Loew, "Rockslide deformation monitoring with fiber optic strain sensors," Natural Hazards and Earth System Sciences, vol. 10, no. 2, pp. 191-201, 2010.

[22] D. Amitrano, M. Arattano, M. Chiarle et al., "Microseismic activity analysis for the study of the rupture mechanisms in unstable rock masses," Natural Hazards and Earth System Sciences, vol. 10, no. 4, pp. 831-841, 2010.

[23] D. Arosio, L. Longoni, M. Papini, M. Scaioni, L. Zanzi, and M. Alba, "Towards rockfall forecasting through observing deformations and listening to microseismic emissions," Natural Hazards and Earth System Sciences, vol. 9, no. 4, pp. 1119-1131, 2009.

[24] L. H. Blikra, "The Åknes rockslide: Monitoring, threshold values and early warning," in Proceedings of 10th International Symposium on Landslides and Engineered Slopes, vol. 30July 4, pp. 1089-1094, Xian, P.R. China, 2008.

[25] A. Helmstetter and S. Garambois, "Seismic monitoring of Séchilienne rockslide (French Alps): Analysis of seismic signals and their correlation with rainfalls," Journal of Geophysical Research: Atmospheres, vol. 115, no. F3, 2010.

[26] A. Lotti, G. Saccorotti, A. Fiaschi et al., "Seismic monitoring of rockslide: the Torgiovannetto quarry (Central Apennines, Italy)," in Proceedings of the Engineering Geology for Society and Territory, G. Lollino, Ed., vol. 2, pp. 1537-1540, Italy, 2014.
[27] V. Pazzi, L. Tanteri, G. Bicocchi, M. D’Ambrosio, A. Caselli, and R. Fanti, "H/V measurements as an effective tool for the reliable detection of landslide slip surfaces: Case studies of Castagnola (La Spezia, Italy) and Roccalbegna (Grosseto, Italy)," Physics and Chemistry of the Earth, Parts A/B/C, vol. 98, pp. 136-153, 2017.

[28] A. Graziani, M. Marsella, T. Rotonda, P. Tommasi, and C. Soccodato, "Study of a rock slide in a limestone formation with clay interbeds," in Proceedings of the International Conference on Rock Joints and Jointed Rock Masses, Tucson, Arizona, USA 7th8th, 2009.

[29] M. Boccaletti, P. Elter, and G. Guazzone, "Plate tectonic models for the development of the western alps and northern apennines," Nature Physical Science, vol. 234, no. 49, pp. 108-111, 1971.

[30] M. Barchi, A. DeFeyter, B. Magnani, G. Minelli, G. Pialli, and B. Sotera, "The structural style of the Umbria-Marche fold and thrust belt," Memorie della Societ $\alpha$ Geologica Italiana, vol. 52, pp. 557-578, 1998.

[31] G. Lavecchia, G. Minelli, and G. Pialli, "The Umbria-Marche arcuate fold belt (Italy)," Tectonophysics, vol. 146, no. 1-4, pp. 125-137, 1988.

[32] E. Tavarnelli, "Structural evolution of a foreland fold-andthrust belt: The Umbria-Marche Apennines, Italy," Journal of Structural Geology, vol. 19, no. 3-4, pp. 523-534, 1997.

[33] R. C. Wilson and D. K. Keefer, Dynamic Analysis of a Slope Failure from the 6 August 1979 Coyote Lake, California, Earthquake, vol. 73, Bulletin of the Seismological Society of America, 1983.

[34] D. K. Keefer, "Landslides caused by earthquakes.," Geological Society of America Bulletin, vol. 95, no. 4, pp. 406-421, 1984.

[35] R. W. Jibson and D. K. Keefer, "Analysis of the seismic origin of landslides: examples from the New Madrid seismic zone," Geological Society of America Bulletin, vol. 105, no. 4, pp. 521536, 1993.

[36] B. Khazai and N. Sitar, "Evaluation of factors controlling earthquake-induced landslides caused by Chi-Chi earthquake and comparison with the Northridge and Loma Prieta events," Engineering Geology, vol. 71, no. 1-2, pp. 79-95, 2004.

[37] M. Locati, R. Camassi, and M. Stucchi, "DBMI11, the 2011 version of the Italian Macroseismic Database. Milano, Bologna," http://emidius.mi.ingv.it/DBMI11, 2011.

[38] D. M. Cruden and D. J. Varnes, "Landslides Types and Processes," in Landslides: Investigation and Mitigation. Transportation Research Board Special Report 247, A. K. Turner and R. L. Schuster, Eds., pp. 36-75, National Academy Press, 1996.

[39] F. Ponziani, N. Berni, C. Pandolfo, M. Stelluti, and L. Brocca, "An integrated approach for the real-time monitoring of a high risk landslide by a regional civil protection office," in Proceedings of the EGU Leonardo Topical Conference Series on the hydrological cycle, pp. 10-12, Luxembourg, 2010.

[40] M. Balducci, R. Regni, S. Buttiglia et al., "Design and built of a ground reinforced embankment for the protection of a provincial road (Assisi, Italy) against rockslide," in Proceedings of the XXIV Conv. Naz. Geotecnica, AGI, 22th-24th, 2011.

[41] M. Nogoshi and T. Igarashi, "On the propagation characteristics estimations of subsurface using microtremors on the ground surface," Journal of the Seismological Society of Japan, vol. 23, pp. 264-280, 1970.

[42] M. Nogoshi and T. Igarashi, "On the amplitude characteristics of microtremor (part 2)," Journal of the Seismological Society of Japan. 2nd ser, vol. 24, no. 1, pp. 26-40, 1971. 
[43] Y. Nakamura, "Method for dynamic characteristics estimation of subsurface using microtremor on the ground surface," Quarterly Report of RTRI (Railway Technical Research Institute) (Japan), vol. 30, no. 1, pp. 25-33, 1989.

[44] Y. Nakamura, "Clear identification of fundamental idea of Nakamura's technique and its applications," 12 WCEE, 2000.

[45] M. Bour, D. Fouissac, P. Dominique, and C. Martin, "On the use of microtremor recordings in seismic microzonation," Soil Dynamics and Earthquake Engineering, vol. 17, no. 7-8, pp. 465474, 1998.

[46] P. Volant, F. Cotton, and J. C. Gariel, "Estimation of site response using the H/V method. Applicability and limits of this technique on Garner Valley Downhole Array dataset (California)," in Proceedings of 11th European Conference Earthquake, p. 13, 1998.

[47] P. G. Malischewsky and F. Scherbaum, "Love's formula and H/V-ratio (ellipticity) of Rayleigh waves," Wave Motion. An International Journal Reporting Research on Wave Phenomena, vol. 40, no. 1, pp. 57-67, 2004.

[48] V. Pazzi, M. Di Filippo, M. Di Nezza et al., "Integrated geophysical survey in a sinkhole-prone area: Microgravity, electrical resistivity tomographies, and seismic noise measurements to delimit its extension," Engineering Geology, vol. 243, pp. 282293, 2018.

[49] M. Del Soldato, V. Pazzi, S. Segoni, P. De Vita, V. Tofani, and S. Moretti, "Spatial modeling of pyroclastic cover deposit thickness (depth to bedrock) in peri-volcanic areas of Campania (southern Italy)," Earth Surface Processes and Landforms, 2018.

[50] A. Lotti, A. M. Lazzeri, S. Beja, and V. Pazzi, "Could ambient vibrations be related to cerithidea decollate migration?" International Journal of Geosciences, vol. 08, no. 03, pp. 286-295, 2017.

[51] V. Pazzi, S. Morelli, F. Fidolini, E. Krymi, N. Casagli, and R. Fanti, "Testing cost-effective methodologies for flood and seismic vulnerability assessment in communities of developing countries (Dajç, northern Albania)," Geomatics, Natural Hazards and Risk, vol. 7, no. 3, pp. 971-999, 2016.

[52] V. Pazzi, S. Morelli, F. Pratesi et al., "Assessing the safety of schools affected by geo-hydrologic hazards: The geohazard safety classification (GSC)," International Journal of Disaster Risk Reduction, vol. 15, pp. 80-93, 2016.

[53] V. Pazzi, A. Lotti, P. Chiara, L. Lombardi, M. Nocentini, and N. Casagli, "Monitoring of the vibration induced on the Arno masonry embankment wall by the conservation works after the May 25, 2016 riverbank landslide," Geoenvironmental Disasters, vol. 4 , no. 1, 2017.

[54] D. Albarello and E. Lunedei, "Combining horizontal ambient vibration components for H/V spectral ratio estimates," Geophysical Journal International, vol. 194, no. 2, pp. 936-951, 2013.

[55] S. Castellaro, "The complementarity of $\mathrm{H} / \mathrm{V}$ and dispersion curves," Geophysics, vol. 81, no. 6, pp. T323-T338, 2016.

[56] V. Pazzi, M. Ceccatelli, T. Gracchi, E. B. Masi, and R. Fanti, "Assessing subsoil void hazards along a road system using H/V measurements, ERTs, and IPTs to support local decision makers," Near surface Geophysics, vol. 16, pp. 282-297, 2018.

[57] H. B. Havenith, D. Jongmans, E. Faccioli, K. Abdrakhmatov, and P. Bard, "Site effect analysis around the seismically induced Ananevo rockslide, Kyrgyzstan," Bulletin of the Seismological Society of America, vol. 92, no. 8, pp. 3190-3209, 2002.

[58] O. Méric, S. Garambois, J.-P. Malet, H. Cadet, P. Guéguen, and D. Jongmans, "Seismic noise-based methods for soft-rock landslide characterization," Bulletin de la Société Géographique de France, vol. 178, no. 2, pp. 137-148, 2007.
[59] S. Gaffet, Y. Guglielmi, F. Cappa, C. Pambrun, T. Monfret, and D. Amitrano, "Use of the simultaneous seismic, GPS and meteorological monitoring for the characterization of a large unstable mountain slope in the southern French Alps," Geophysical Journal International, vol. 182, no. 3, pp. 1395-1410, 2010.

[60] M. Horike, B. Zhao, and H. Kawase, "Comparison of site response characteristics inferred from microtremors and earthquake shear waves," Bulletin of the Seismological Society of America, vol. 91, no. 6, pp. 1526-1536, 2001.

[61] S. Parolai and J. J. Galiana-Merino, "Effects of transient seismic noise on estimates of $\mathrm{H} / \mathrm{V}$ spectral ratio," Bulletin of the Seismological Society of America, vol. 96, pp. 228-236, 2006, https://doi.org/10.1785/0120050084.doi.

[62] F. Vallianatos and G. Hloupis, "HVSR technique improvement using redundant wavelet transform," in Increasing Seismic Safety by Combining Engineering Technologies and Seismological Data, NATO Science for Peace and Security Series C: Environmental Security, pp. 117-137, Springer Netherlands, Dordrecht, 2009.

[63] M. Mucciarelli, M. R. Gallipoli, and M. Arcieri, "The stability of the horizontal-to-vertical spectral ratio of triggered noise and earthquake recordings," Bulletin of the Seismological Society of America, vol. 93, no. 3, pp. 1407-1413, 2003.

[64] T. T. Tuan, F. Scherbaum, and P. G. Malischewsky, "On the relationship of peaks and troughs of the ellipticity $(\mathrm{H} / \mathrm{V})$ of Rayleigh waves and the transmission response of single layer over half-space models," Geophysical Journal International, vol. 184, no. 2, pp. 793-800, 2011.

[65] V. Del Gaudio, S. Muscillo, and J. Wasowski, "What we can learn about slope response to earthquakes from ambient noise analysis: An overview," Engineering Geology, vol. 182, pp. 182200, 2014.

[66] J. Burjánek, J. R. Moore, F. X. Yugsi Molina, and D. Fäh, "Instrumental evidence of normal mode rock slope vibration," Geophysical Journal International, vol. 188, no. 2, pp. 559-569, 2012.

[67] D. Albarello, "Possible effects of regional meteoclimatic conditions on HVSR," in Proceedings of the ATO SfP 980857 - II Intermediate Meeting, pp. 25-27, 2006.

[68] T. Tanimoto, S. Ishimaru, and C. Alvizuri, "Seasonality in particle motion of microseisms," Geophysical Journal International, vol. 166, no. 1, pp. 253-266, 2006.

[69] R. F. Lee, R. E. Abbott, H. A. Knox, and A. Pancha, "Seasonal changes in H/V spectral ratio at high-latitude seismic stations," in Proceedings of the American Geophysical Union - AGU, Fall Meeting, 2014.

[70] M. Mucciarelli, M. R. Gallipoli, D. Di Giacomo, F. Di Nota, and E. Nino, "The influence of wind on measurements of seismic noise," Geophysical Journal International, vol. 161, no. 2, pp. 303308, 2005. 

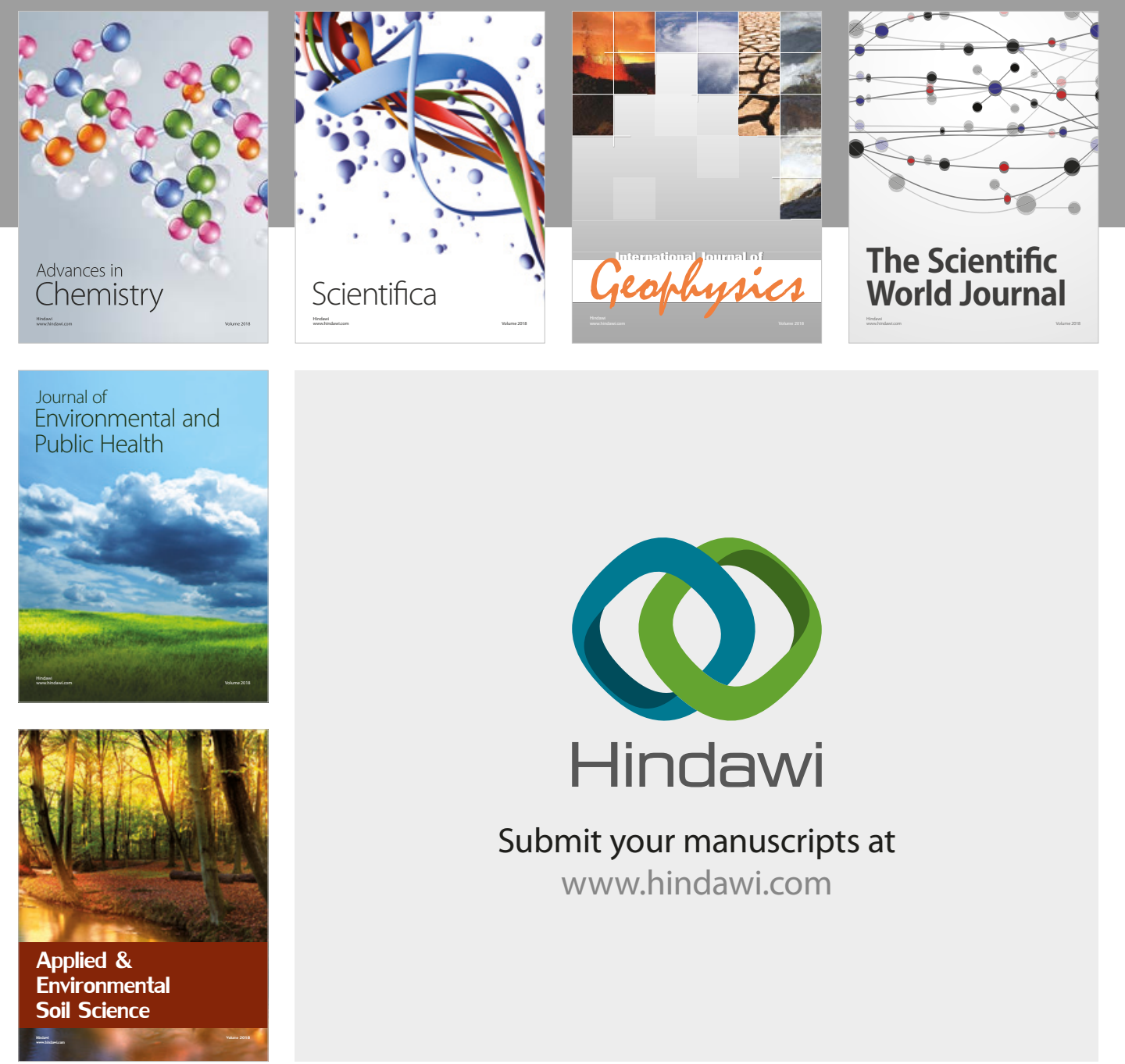

The Scientific

\section{World Journal}
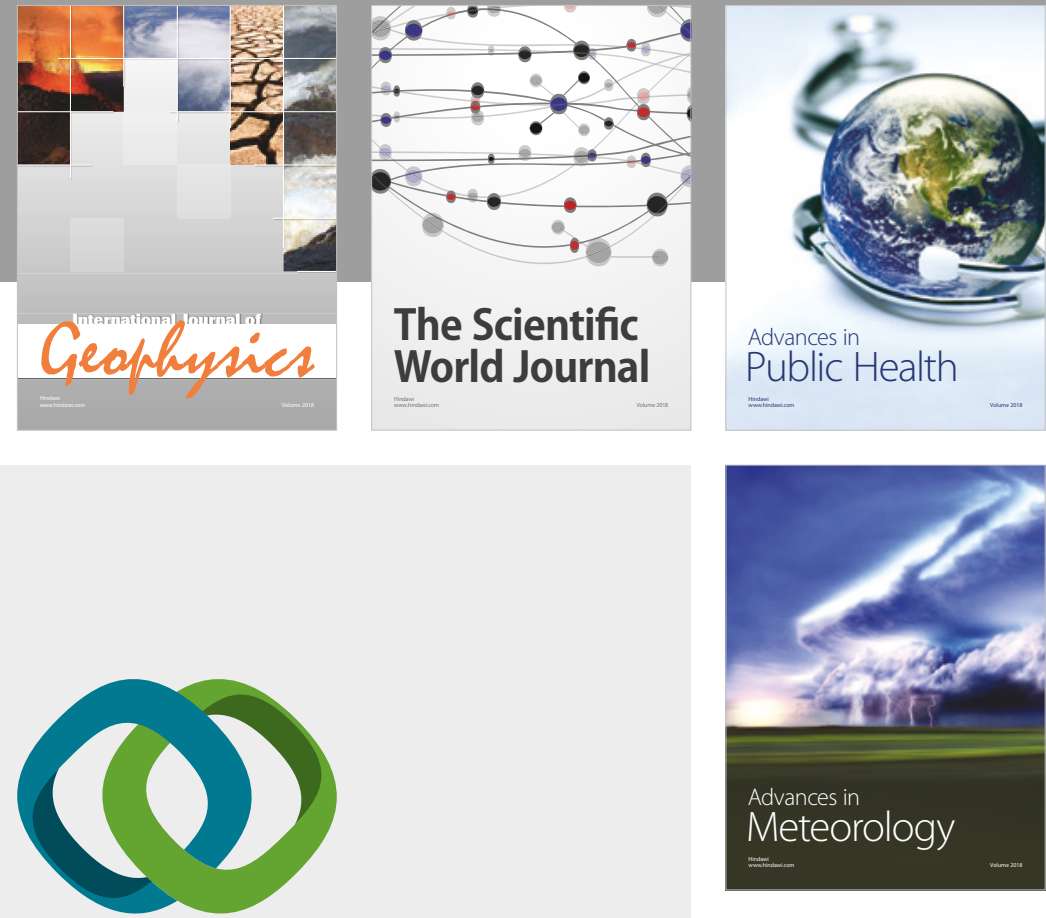

Advan

Public Health

\section{Hindawi}

Submit your manuscripts at

www.hindawi.com
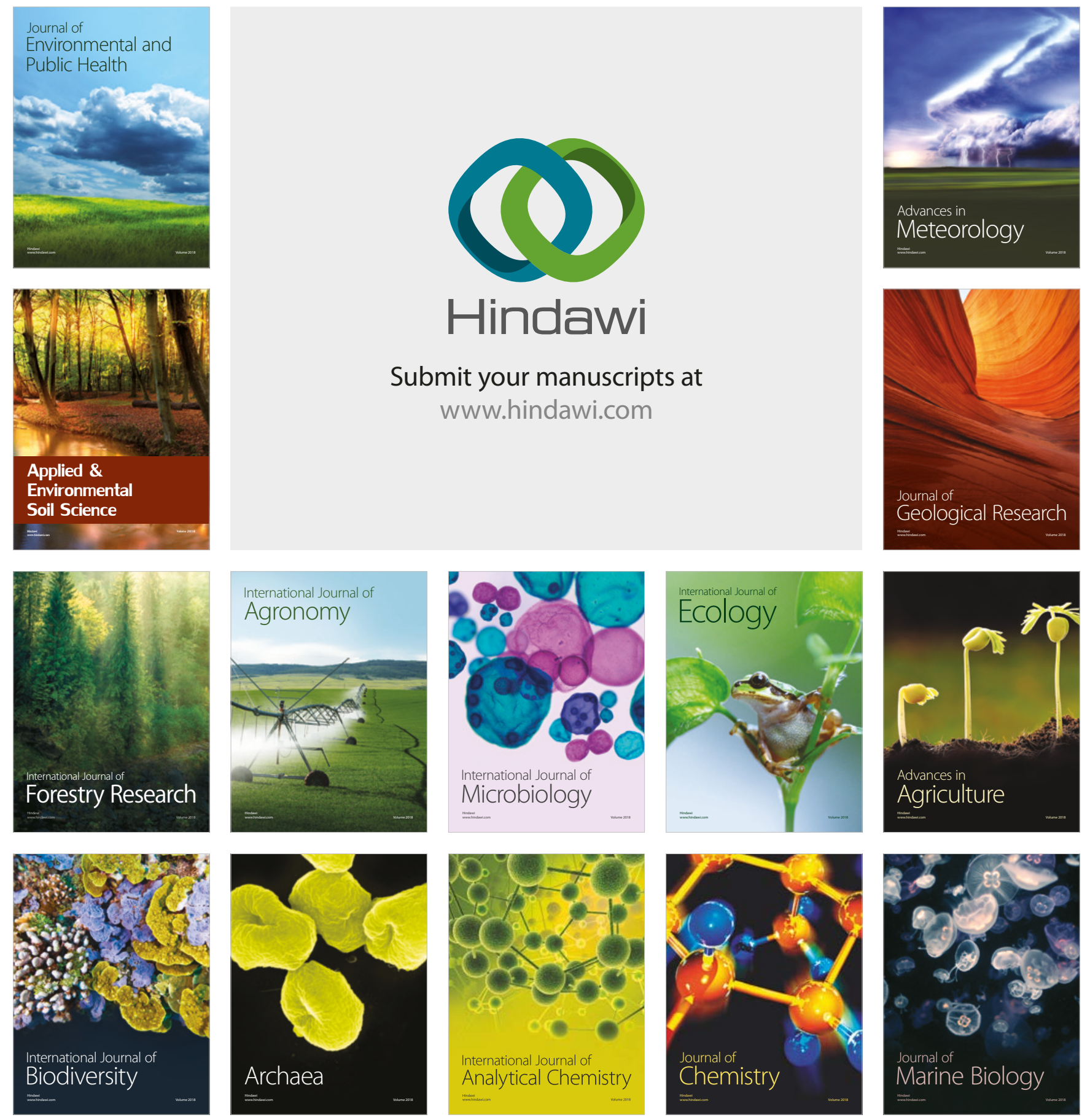